\title{
Management of mandibular second premolar agenesis
}

\author{
M. Medio ${ }^{1,2}$, A. Popelut ${ }^{3}$, M. De La Dure Molla 2,4 \\ 1 CECSMO 4, Paris 7 Denis Diderot University, Pitié Salpêtriére Hospital, AP-HP (Paris Hospitals \\ Board), France \\ 2 Orofacial Deformities Reference Center, Rothschild Hospital, Paris, France \\ 3 Private periodontal and implantology practice, Courbevoie, France \\ 4 Pediatric odontologist, Paris 7 Denis Diderot University, Odontology Center, Rothschild Hospital, \\ AP-HP (Paris Hospitals Board), France
}

\begin{abstract}
In Europe, dental agenesis affects $5.45 \%$ of the population. Apart from third molars, the mandibular second premolars are most often affected. For each clinical situation, the orthodontist must select the best treatment option to manage the edentulous space.

This space can be closed or left open.

If the space is to be closed, the goal is to achieve stable and functional occlusal relationships without negative impact on profile.

If the space is to be left open, the goal is to create a space suitable for future prosthetic restoration, render the dental axes parallel, and maintain optimal bone volume, especially if the deciduous molar is in infra-occlusion.

In this paper we present various treatment options for managing mandibular second premolar agenesis.
\end{abstract}

\section{KEY WORDS}

Dental agenesis, mandibular second premolars, infra-occlusion of deciduous molars, orthodontics, decision-making

\section{INTRODUCTION}

Dental agenesis is the most common hereditary dental pathology. Prevalence in Europe is $5.45 \%{ }^{28}$. All teeth, deciduous and definitive, may be involved, and it may be isolated or associated with multiple deformity syndromes. In most cases (83\%), only one or two teeth are involved; oligodontia (>6 ageneses) is much rarer $(0.14 \%)$.

The genetic origin is now established ${ }^{38}$. Mutations in the Msx1, Pax9 and Axin2 genes have been reported in isolated forms, but do not explain all cases. Genes implicated in syndromic forms, such as Eda1 and Wnt10a, have been reported in ectodermal dysplasia as well as in isolated dental agenesis.

Polder's meta-analysis described distribution, with certain teeth often missing and others rarely: apart from $3^{\text {rd }}$ molars, the teeth most frequently concerned are the 


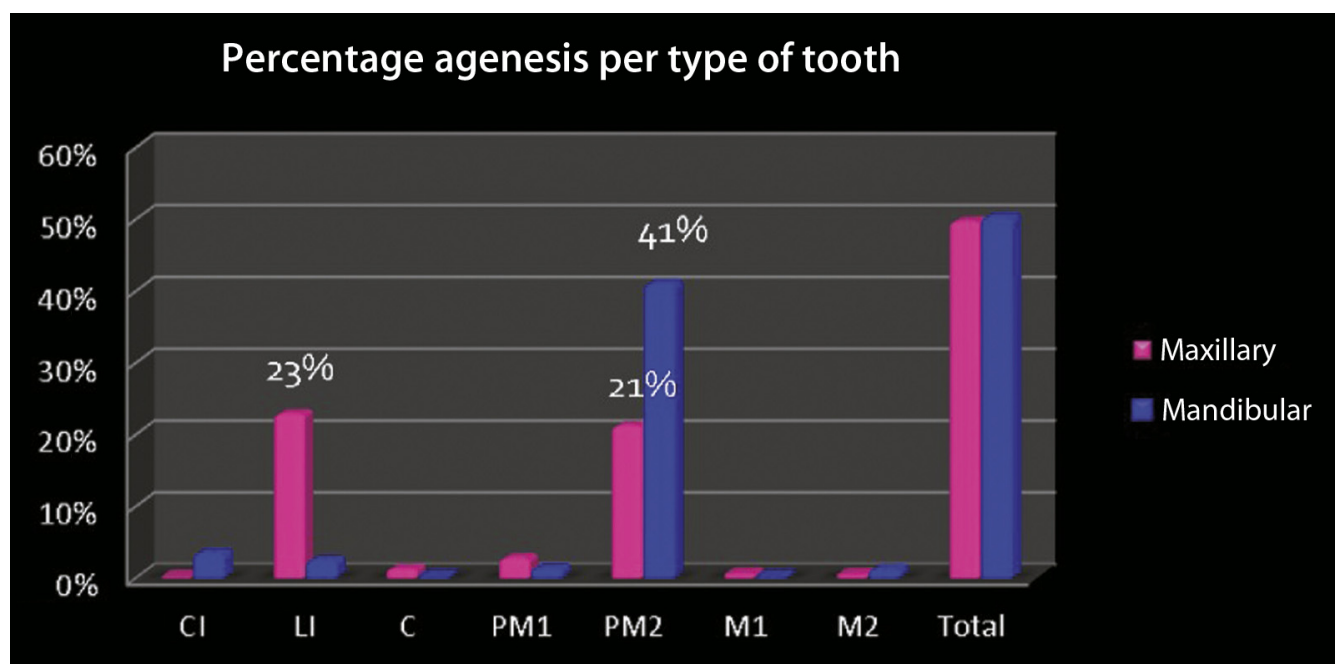

Figure 1

Distribution of dental agenesis: the mandibular premolars are the most often affected (apart from the $3^{\text {rd }}$ molars).

mandibular $2^{\text {nd }}$ molars $(41 \%)$, followed by the lateral maxillary incisors (23\%) (Fig. 1).

Dental agenesis has frequently been found to be associated with other dental morphogenetic abnormalities: lateral maxillary incisor microdontia, maxillary canine palatine inclusion, delayed development or deciduous molar infra-occlusion ${ }^{3}$. Peck described this as a "pattern of dental anomalies", more often associated than isolated, suggesting a shared genetic origin. Such patients constitute $25 \%$ of the orthodontic population ${ }^{27}$.

In case of agenesis of at least 1 premolar, deciduous molar infra-occlusion is more frequent, at $24.6 \%{ }^{8}$. It results from arrested deciduous eruption without physical obstacle after emergence $^{2}$ : the infra-positioned tooth remains stationary while surrounding growth continues (Fig. 2). It may occur with or without an underlying definitive tooth germ ${ }^{17}$.
Etiology is little known. There are two main theories. Biederman hypothesized impaired alveolodental ligament metabolism, inducing dental ankylosis ${ }^{4}$. Kurol suggested a familial genetic origin, with prevalence varying between populations ${ }^{21}$. At all events, the pathophysiology of deciduous molar infra-occlusion involves dental ankylosis ${ }^{19}$. Histologic studies reported ankylosis areas in these teeth, which is confirmed by the difficulty of extraction.

Prevalence of deciduous molar infra-occlusion varies in the literature between $1.3 \%$ and $38.5 \%$, depending on ethnicity ${ }^{35}$.

The teeth most often involved are the deciduous mandibular $2^{\text {nd }}$ molars, the mandible being more often affected than the maxilla ${ }^{30}$.

Diagnosis is founded on clinical and radiological examination. Infraocclusion may be unilateral (Fig. 3). 


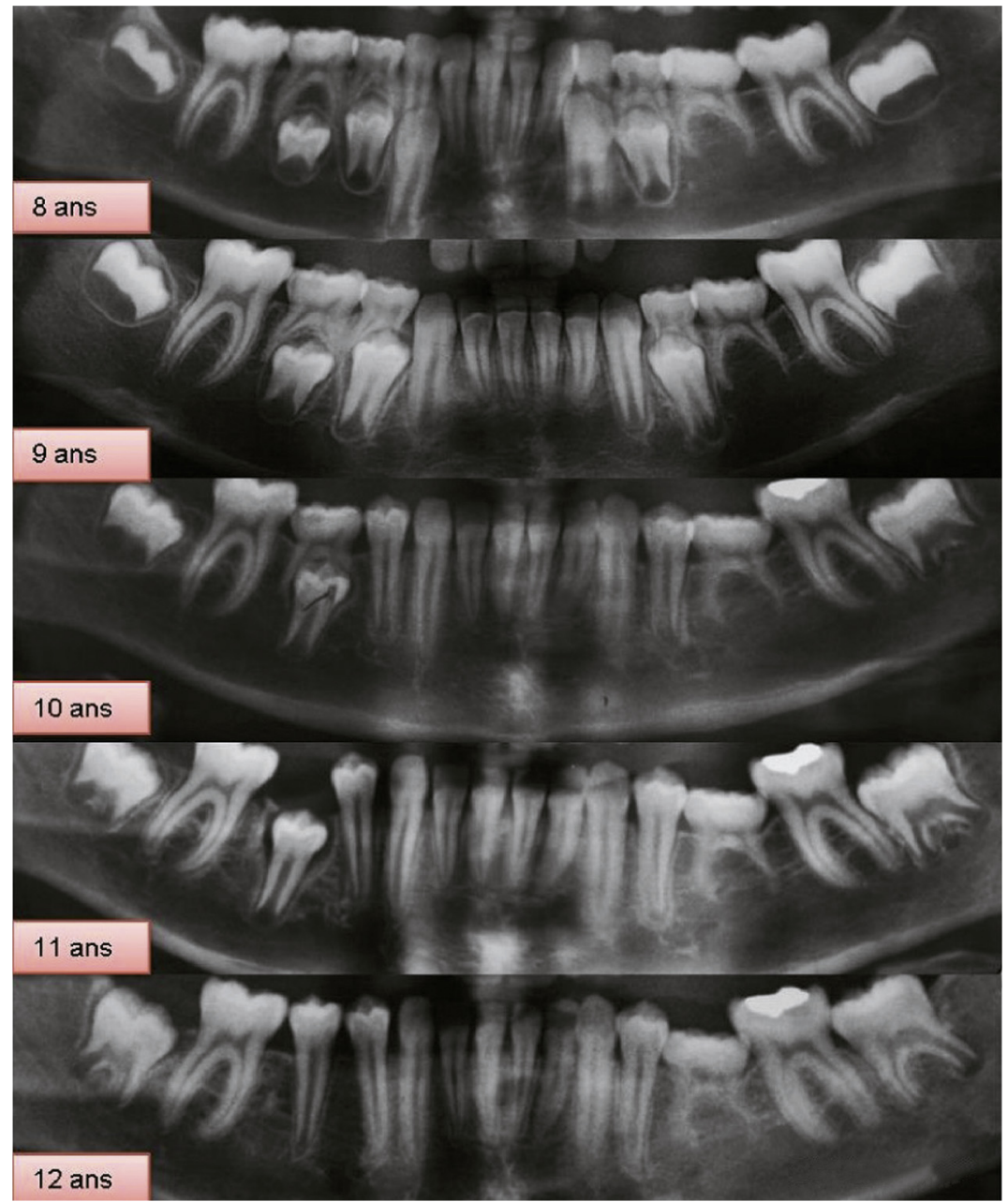

Figure 2

Series of panoramic radiographs taken between 8 and 12 years of age at 1-year intervals, showing relative reinclusion of 75 . Following extraction of 85, 45 developed normally.

\section{TREATMENT DECISION-MAKING IN MANDIBULAR $2^{\text {ND }}$ MOLAR AGENESIS}

Early diagnosis of premolar agenesis is hindered by delayed calcification. By the age of 8 years, the dental follicle or germ should be visible on X-ray, but this may not be the case until around 11 years of age ${ }^{23}$.

Orthodontic management may not include deciduous molar extraction and space closure.
Several authors raised the great question: to open or to close?

\section{Treatment decision-making factors}

Age

Age at diagnosis influences treatment strategy. If diagnosis is earlier 


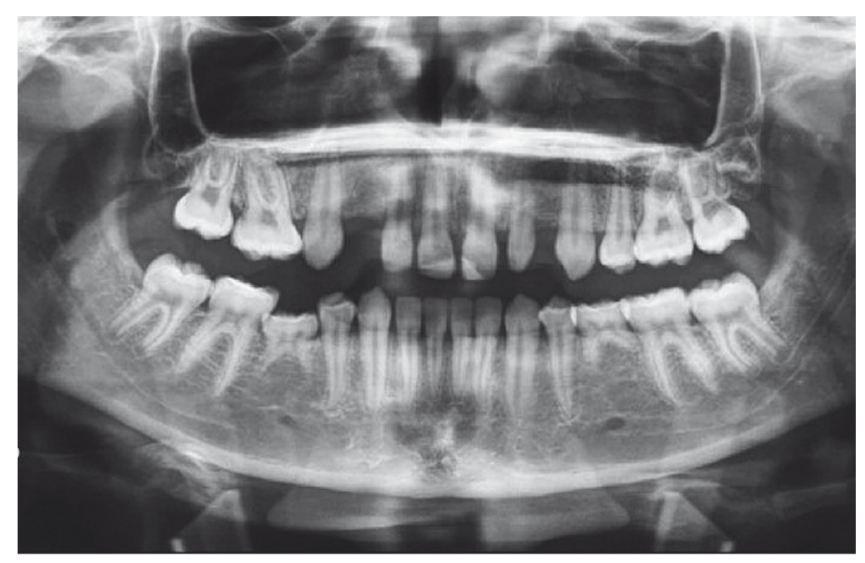

Figure 3

Panoramic radiograph in a 13 year-old girl with agenesis of $14,15,18,25,35,38,45$ and 48 and moderate infra-occlusion of 85 but not 75 .

than the development of the definitive $2^{\text {nd }}$ molar, all options are open ${ }^{14}$.

If, on the other hand, dentition is definitive, closure is liable to have esthetic repercussions.

\section{Facial typology}

Facial typology is a fundamental factor in choosing between opening or closure.

In hypodivergent subjects, the treatment objective is to avoid worsening the profile and therefore to avoid extraction but rather retain the agenetic spaces. In hyperdivergent subjects, on the other hand, it is better to extract the premolars and perform mandibular closure to improve lip occlusion at rest.

Björk described a qualitative analysis of the various types of mandibular rotation ${ }^{7}$. In hypodivergent subjects, the bone is denser and orthodontic movements to close extraction and/ or agenetic spaces are more difficult, notably in the mandible.

\section{Skeletal and dental disorders}

Agenetic space closure is the most attractive solution in young patients, avoiding implants. Treatment options, however, depend on orthodontic diagnosis ${ }^{29}$. Usually, closure is indicated when extraction is necessary to resolve dentomaxillary disharmony: i.e., bilabioversion and/or crowding (Fig. 4).

\section{Number of dental ageneses}

The number of ageneses also determines treatment options. In severe oligodontia, closure of spaces would lead to very short arcades, impairing mastication (Fig. 5).

\section{Deciduous molar integrity}

Decay, large obturation, root resorption or infra-occlusion may reduce deciduous molar lifetime. If molar infraocclusion is severe, the vertical defect will be large and some authors recommend extraction ${ }^{18}$. If deciduous molar integrity is unimpaired, the tooth 


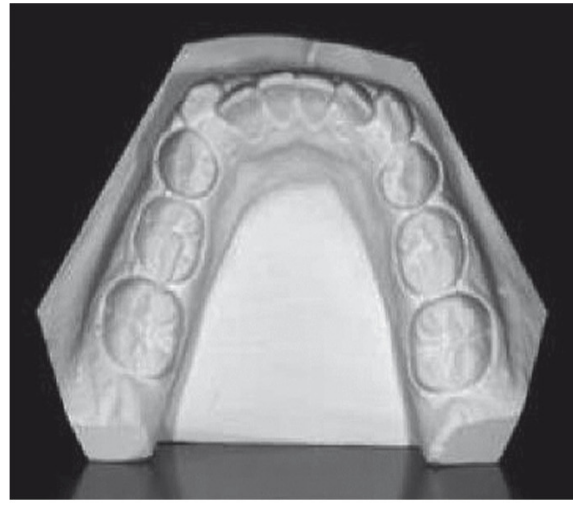

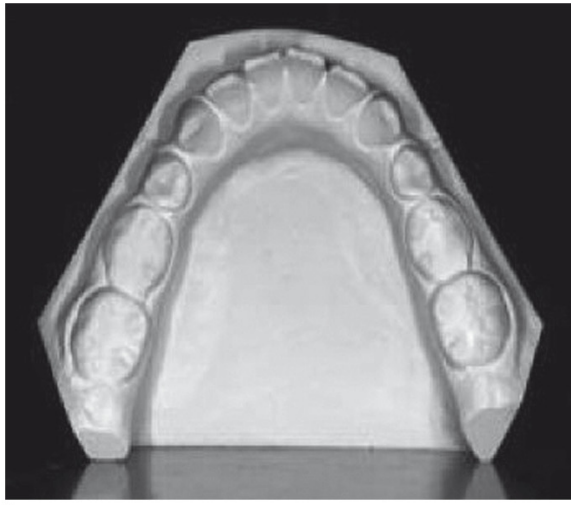

$\mathrm{b}$

Figure 4

Mandibular casts of 2 patients during constitution of young adult dentition, with persistence of 75 and 85 in moderate infra-occlusion. a) Anterior crowding with no room for 33 and 43 to develop. b) Diastema generalized from 34 to 44.

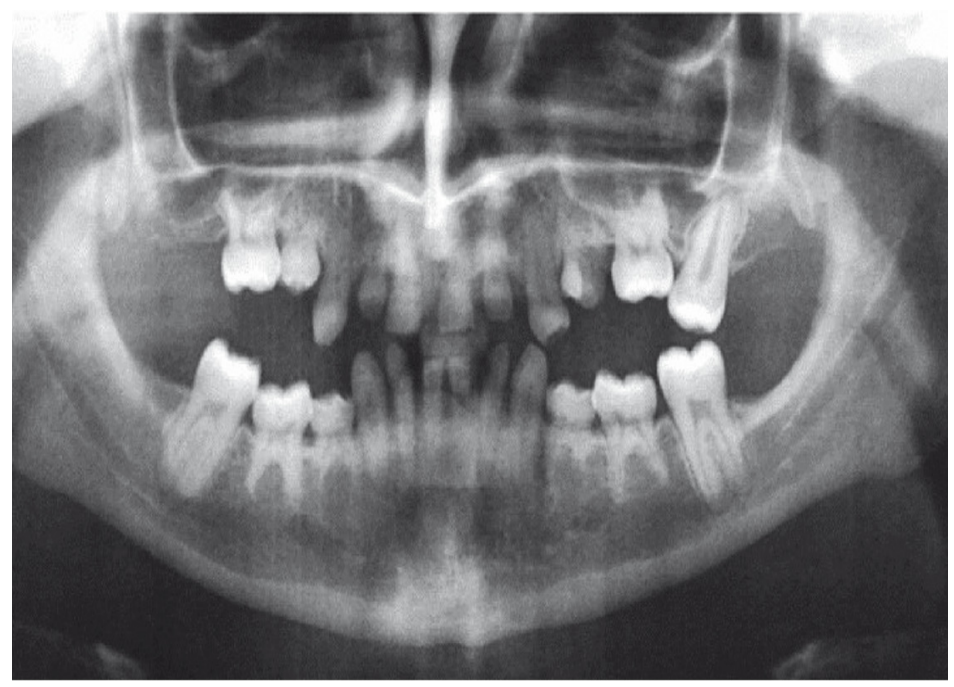

Figure 5

Panoramic X-ray of severe oligodontia with all 8 deciduous molars in infra-occlusion.

can usefully be spared, to as a space maintainer ${ }^{33}$.

\section{Extraction of ankylosed deciduous teeth}

Ankylosis seems to be associated with deciduous molars showing infraocclusion; alveolar bone-loss following extraction may be severe, jeopardizing future implantation and the whole orthodontic plan ${ }^{16}$.

\section{Motivation of patients and parents}

Orthodontic treatment involving closures can be long, requiring good cooperation and motivation. 


\section{Closure of mandibular $2^{\text {nd }}$ premolar agenesis space}

In dentomaxillary disharmony, the space corresponding to the absent premolar allows correction of crowding or incisor axis; but closure should be avoided if it would impair profile or occlusion.

\section{Extraction and spontaneous closure}

The deciduous molar may be extracted at a very early point, allowing physiological closure. Joondeph and McNeill recommend extraction before the age of 11 (i.e., before eruption of the definitive $2^{\text {nd }}$ molar) so as to allow such spontaneous closure ${ }^{11}$.

The mandibular $2^{\text {nd }}$ premolar crown mineralizes between 2 and 7 years of age. Before the deciduous molar is extracted, it should be checked that the premolar is indeed lacking, with a differential diagnosis of late development. Before extraction, a slice may be performed, to reduce the mesiodistal diameter of the deciduous molar ${ }^{37}$

\section{Hemisectioning of the deciduous molar}

Some authors recommend initial hemisectioning of the distal part of the deciduous molar, to promote spontaneous mesialization without version of the definitive $1^{\text {st }}$ molar, followed by extraction of the mesial part of the deciduous molar in a second step $^{25}$. This allows control of molar anchorage loss without impairing the profile.

\section{Extraction and orthodontic closure}

An orthodontic apparatus is often required for agenesis space closure, to restore arcade continuity. If necessary, anterior anchorage can be reinforced by conjoining the anterior sector and exerting active radiculo-lingual torque on the mandibular incisors. Canine tip-forward can be associated, to prevent distal version.

In mandibular agenesis space closure, impact on the profile can be hard to avoid: anchorage can be reinforced, for example by mini-screws.

Closure may require extraction of premolars in other sectors, to improve occlusion: either contralaterally to restore arcade symmetry, or antagonistically to improve molar relations, or both. In class II or III therapy, occlusion balance may be considered.

It is, however, often a mistake to extract the deciduous molars and close the spaces when there is no dentomaxillary disharmony, especially in hypodivergent patients (Fig. 6).

\section{Retaining mandibular $2^{\text {nd }}$ premolar agenesis spaces}

When there is no crowding, the treatment decision is harder to make, especially when prognosis for the deciduous molar is poor ${ }^{22}$.

\section{Intact deciduous molar}

If it is decided to retain the agenetic premolar spaces, it is preferable to conserve the deciduous molar as long as possible, despite a risk of infra-occlusion or root resorption. 


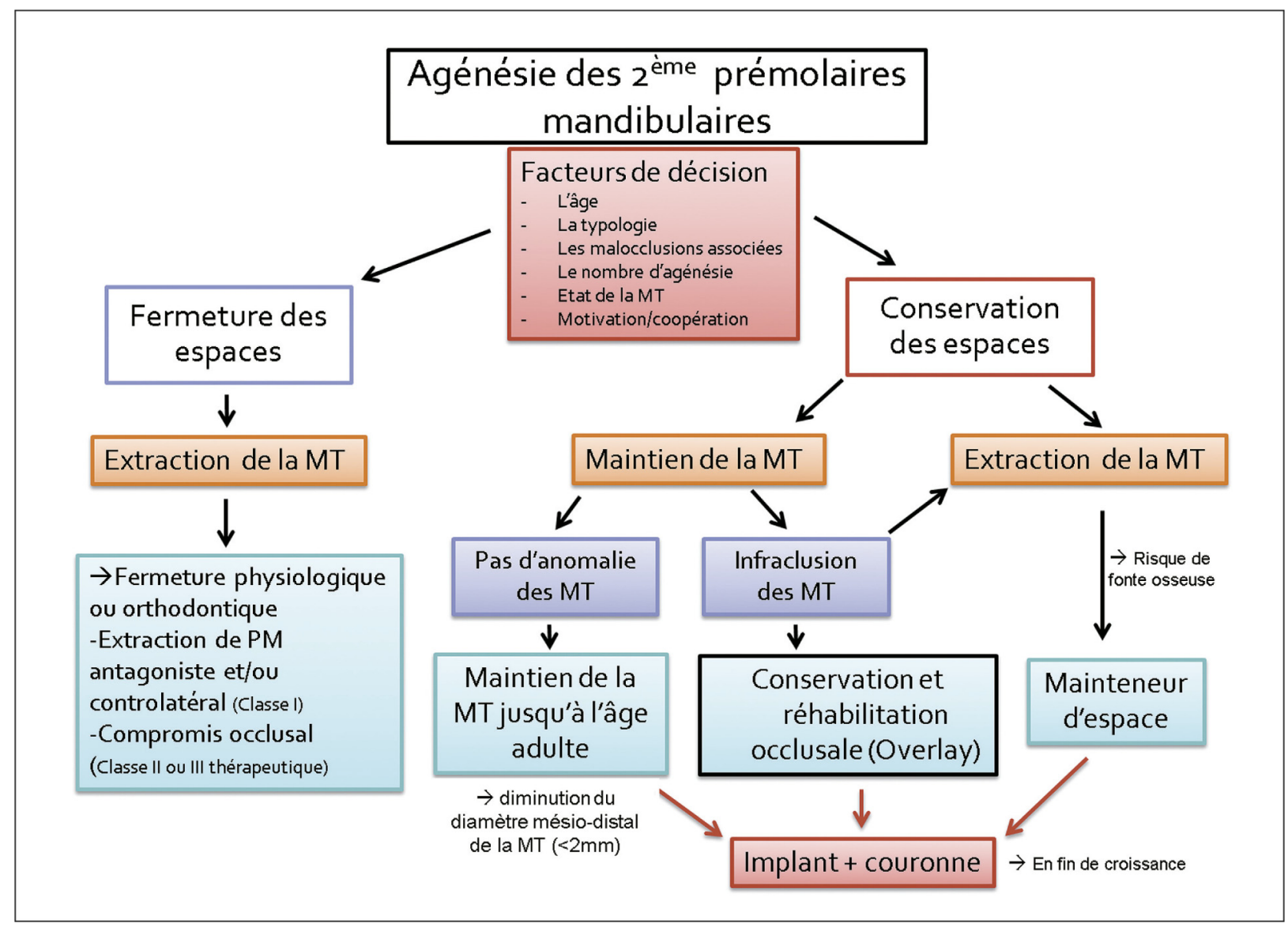

Figure 6

Decision tree in premolar agenesis. Medio et al., International Orthodontics 2014;12(3):291-302.

Sabri considers the deciduous molar to be the best means of maintaining the space and bone volume ${ }^{29}$. Many studies have shown that deciduous molars can be conserved for several years; their lifetime is hard to predict at an early stage, when decisions have to be taken, but root resorption is very slow. If the deciduous molar persists at 20 years of age, its prognosis is very good ${ }^{5}$.

Deciduous molar root resorption is negligible for several years; conservation often proves a more lasting solution that implantation ${ }^{33}$.
Conserving the deciduous molar conserves bone volume ahead of implantation. However, mesiodistal diameter should be reduced, as the deciduous molar is wider than a 1.2-mm premolar, so as obtain a space suited to future implantation ${ }^{15}$.

Arranging for a 7-mm space allows class I molar relations ${ }^{34}$. Reduction, however, is guided by the divergence of the roots and size of the pulp, to avoid inflammatory reaction ${ }^{29}$; otherwise a compromise has to be struck regarding molar occlusion. According to Kokich, when the alveolus of the 
adjacent tooth is in contact with the root of the deciduous tooth, the latter is resorbed.

The deciduous molar may appear in infra-occlusion, but this is not a problem for its survival $^{5}$.

\section{Deciduous molar in infra-occlusion}

In slight to moderate infra-occlusion, the deciduous tooth may be conserved, to prevent bone loss for future implantation. The tooth should be reconstituted, to restore occlusal and interproximal contact ${ }^{1}$ and prevent version of the adjacent teeth and protrusion of the antagonists ${ }^{36}$. Several treatment options have been described to restore function ${ }^{13}$ : metal crowns, preformed pedodontic crowns, or direct or indirect composite restoration.

A deciduous molar may begin the process of "relative reinclusion" at 6-13 years of age. If infra-occlusion appears in a 13 year-old girl with already well-established craniofacial growth, it will not be unduly severe and may be managed by a composite to restore occlusal contact ${ }^{29}$. There is little worsening of infra-occlusion in adolescents, with mean progression of $0.5 \pm 0.26 \mathrm{~mm} /$ year $^{22}$.

Prognosis for infra-occlusion depends on the severity of root resorption. Severity tends to increase during growth and to plateau with adulthood. In over-12 year-olds with mild infra-occlusion, the deciduous molar may be conserved with good prognosis. In under-12 year-olds, prognosis is much more uncertain ${ }^{9}$.

\section{Extracted deciduous molar}

For many years, infra-occluding teeth were considered as a source of occlusion disorder and were almost systematically extracted. As the cause is usually ankylosis, extraction may lead to considerable bone loss, complicating future implantation ${ }^{16}$.

Nowadays, extraction is recommended only in case of abscess or severe decay or if infra-occlusion is severe and the occlusion line is near the gum ${ }^{20}$.

One should not wait until the deciduous molar is in excessive infraocclusion, as this incurs a risk of onset of severe vertical bone defect ${ }^{10}$; an implant will then be deeply embedded and clinical crown height will be increased. To avoid such vertical defect, bone graft may be performed or the bone may be remodeled by distalizing the $1^{\text {st }}$ premolar toward the missing $2^{\text {nd }}$ premolar and implanting in the $1^{\text {st }}$ premolar site ${ }^{34}$ although this considerably lengthens treatment.

Avulsion should be performed nontraumatically, possibly by separating the roots so as to maintain the alveolar walls.

To avoid excessive bone loss during growth, some authors recommend extracting the deciduous molar while infra-occlusion is still moderate. Studies have demonstrated that the bone level at the extraction site migrates occlusally during growth of the adjacent teeth, which continue erupting ${ }^{26}$. Periosteal stretching stimulates osteoblast activity, allowing alveolar growth to continue in the space. 
The drawback with early deciduous $2^{\text {nd }}$ molar extraction lies in the thinning of the bone crest: alveolar crest thickness in the space is reduced by $25 \%$ over the first 3 years (from 11.5 $\mathrm{mm}$ to $8.5 \mathrm{~mm}$ ), then by $4 \%$ over the following 4 years ${ }^{26}$, more on the vestibular than on the lingual side ${ }^{15}$.

If for whatever reason (decay, severe infra-occlusion, excessively resorbed roots) the deciduous molar is extracted, a space maintainer is required awaiting implantation: band/ crown and loop, Nance palatal arch, lingual arch, dental tray; pediatric implants can also be created.

\section{Deciduous molar replacement solutions}

There are several replacement solutions at end of growth.

- Tooth-borne bridge

Tooth-borne bridges require damaging the teeth adjacent to the space; if these are healthy, this solution seems excessive.

- Extension bridge

Some authors have described cantilever bridges for premolar replacement, fitted to the occlusal and lingual sides of the definitive $1^{\text {st }}$ molar. Sidhu reported a patient with moderate or severe infra-occlusion of 54, 55 and 65; after extracting the 3 deciduous molars, the 55 and 65 spaces were closed orthodontically to achieve therapeutic class II relations and 14 was restored using a ceramic prosthetic element fixed to $16^{31}$. However, studies of posterior extension bridges reported poorer survival than for conventional bridges or implant-borne restoration.

- Autotransplantation

It is possible to do an autotransplant using a premolar that is being extracted for orthodontic reasons, to replace another premolar ${ }^{32}$.

It is also possible to autotransplant the maxillary $3^{\text {rd }}$ molar to replace the lacking premolar ${ }^{24}$.

To achieve the best results, the optimal age for $3^{\text {rd }}$ molar autotransplant is around 17-18 years. The transplanted tooth should not be completely edified; the root should be between one-half and two-thirds of radicular height ${ }^{12}$.

Reports of autotransplantation are sparse: the transplanted tooth is subject to ankylosis and survival is poorer than for an implant; moreover, few surgeons are trained for this procedure.

- Implantation

In agenesis flanked by healthy teeth, the most common solution is an implant-borne crown at end of growth $^{39}$.

In severe infra-occlusion, adjacent teeth may show version, and orthodontic treatment is required to correct their axes and restore a space suitable for future implantation.

Single-unit implantation is reliable in the long term, but cost is a factor to be borne in mind. 5-year survival is 93-95\%, so that regular follow-up is needed, with implantation possibly repeated at several points over the patient's lifetime. 


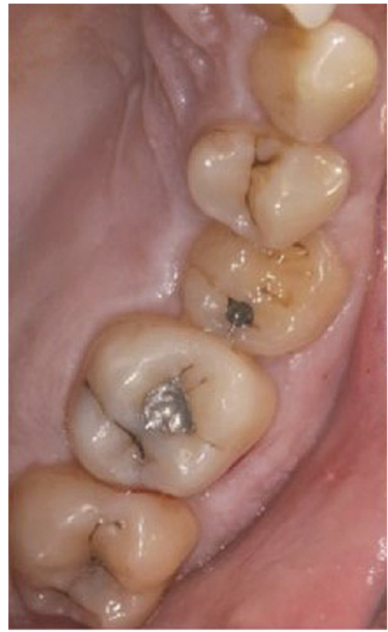

a

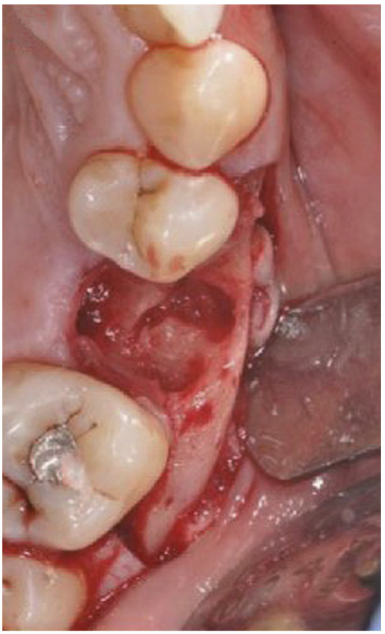

b

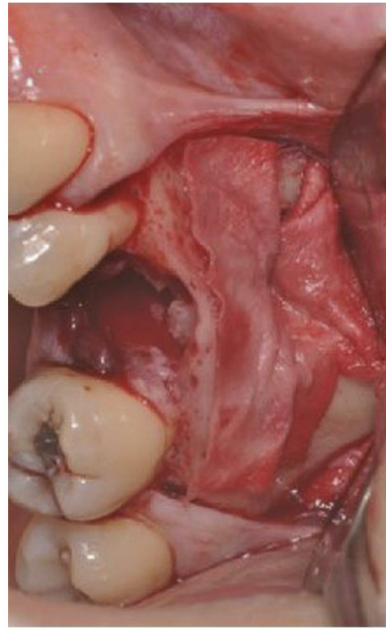

C

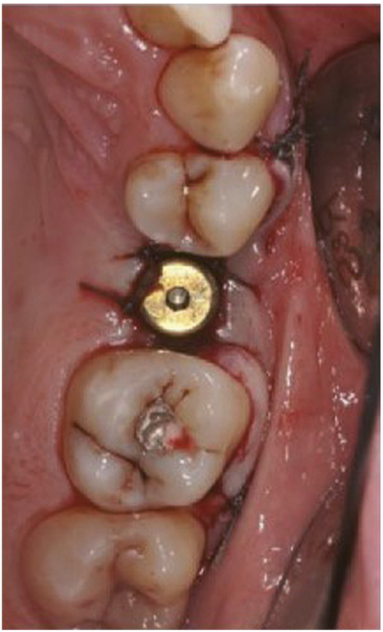

d

Figure 7

a) Severe 55 infra-occlusion. b) Non-traumatic extraction of 55 with root separation and maximal alveolar wall sparing.

c) Sinus elevation on lateral approach; bone filling with resorbable membrane. d) Implant positioning to replace 15.

If vertical and/or bone defect is too great, autologous or synthetic bone graft is required to increase bone volume. Support tissue may also need thickening by pre- or intra-operative gingival graft at implantation. If the deciduous molar is maxillary, sinus elevation may be necessary if residual sub-sinus height is insufficient for the implant (Fig. 7).

\section{Case report (Fig. 8)}

Iona B., aged 20 years, consulted for esthetic and functional reasons. Esthetically, the lower face was diminished, her smile unpleasing, and cervico-mental distance was reduced, with double-chin aspect. Dentally, formula was incomplete: 15, 25, 35 and 45 absent; 55, 65, 75 and 85 totally submerged; and 55, 75 and 85 in severe infra-occlusion. Malocclusion was class II.2 with 5-mm class II left and right molar and canine relation, severe maxillary incisor lingual version and 6-mm supra-occlusion.

The treatment plan was orthodonticsurgical, with maxillary and mandibular multi-attachment apparatuses, reopening of 15, 25, 35 and 45 spaces, and mandibular advancement.

The dental arcades were aligned then straightened and the $1^{\text {st }}$ molar axes corrected. During orthodontic treatment, teeth in infra-occlusion were extracted and the spaces conserved. Surgical arches were fitted and 5-mm mandibular advancement was performed ( $\mathrm{Dr}$ Deffrennes). Some occlusal finishing was required; the agenetic premolar spaces were made symmetrical $(7 \mathrm{~mm})$. Then 4 implants $\left(\right.$ Nobel $^{\circledR}$, Replace, Tapered and NP) were inserted (Dr Popelut). Implant-borne crowns were screwed on 3 months after implant osseointegration. 

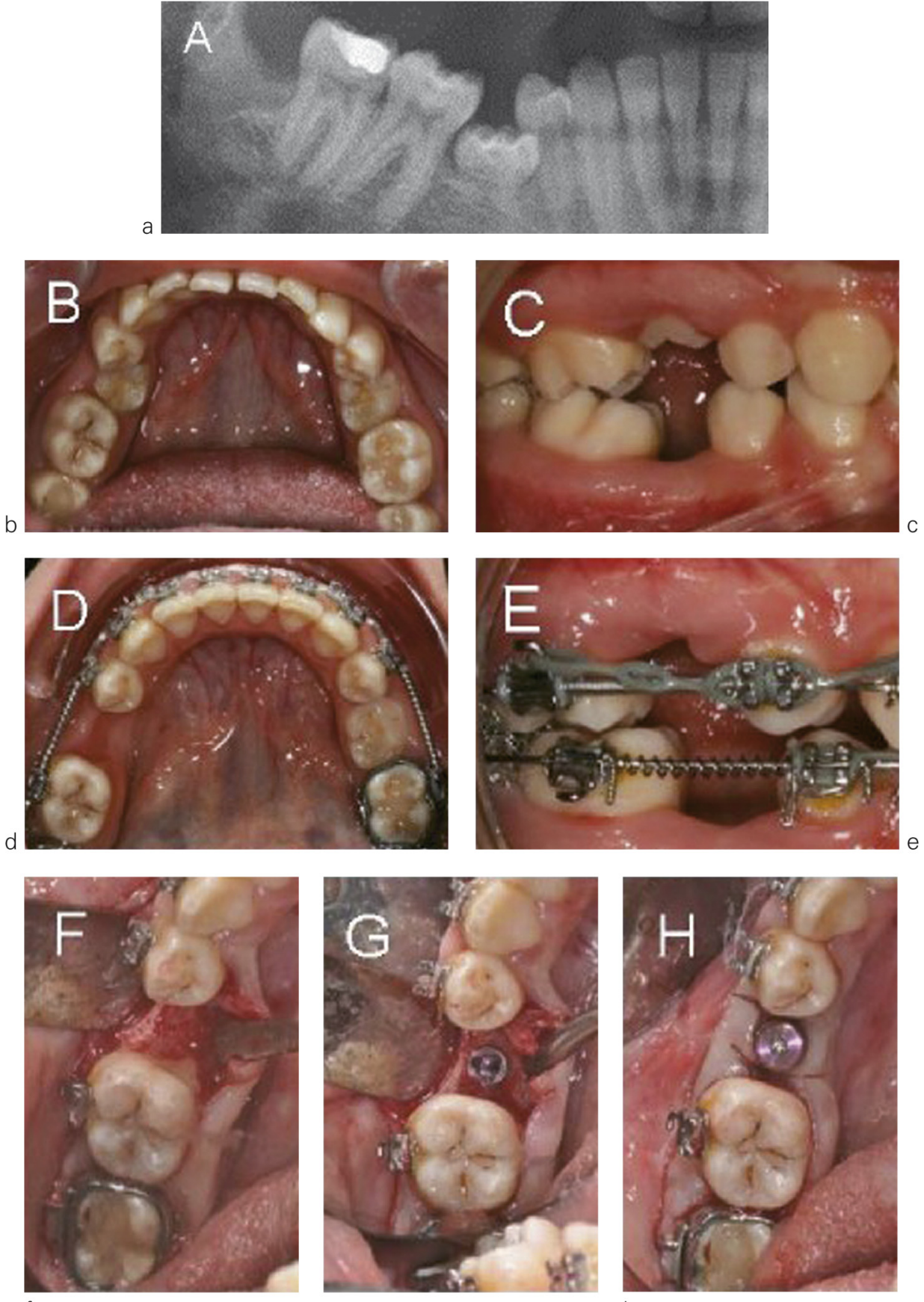

f

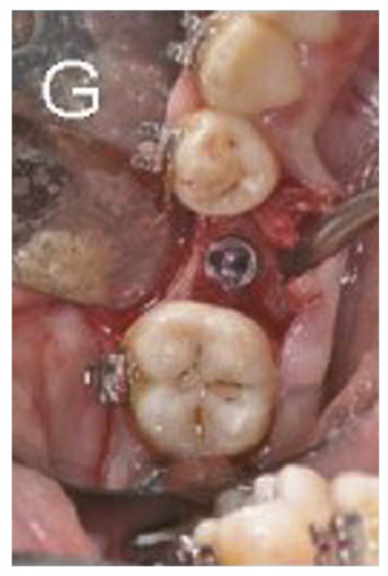

g

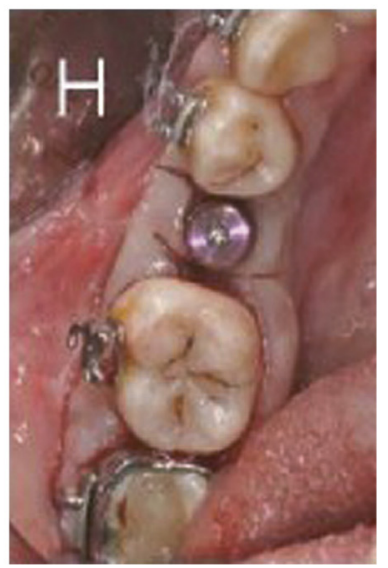

h
Figure 8

a) Panoramic radiograph showing severe 85 infra-occlusion and version of adjacent teeth. b) and c) Reduced space for 45, with mesial version of 46 and 5-mm class II molar-canine relation. d) and e) Correction of 46 and 44 axes by maxillary and mandibular multi-attachment apparatus. Mandibular advancement surgery (Dr Deffrennes) restored class I molar relation. f), g) and h) Implantation to 45 (Dr Popelut). i) Panoramic radiograph showing implant replacing 45, parallel to mandibular roots.

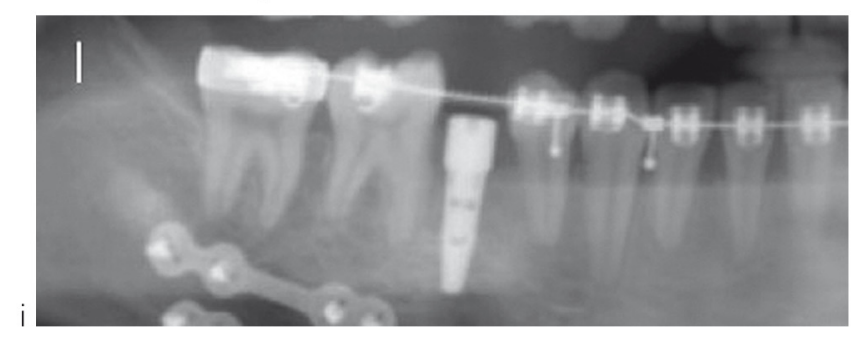




\section{CONCLUSION}

In mandibular $2^{\text {nd }}$ molar agenesis, orthodontics offers several reliable solutions. The risks associated with agenesis space closure are reduced by the use of skeletal anchors (miniscrews and mini-plates). In the absence of dentomaxillary disharmony, however, retaining the spaces is the best option. If the deciduous molar is in infra-occlusion, there are several possible solutions, according to the clinical situation. In the long term, the agenetic premolar will be replaced by an implant-borne crown. Space management is therefore multidisciplinary, and communication between practitioners is essential.

\section{Acknowledgments: Dr Martine Barbary.}

Conflicts of interest: The author declares no conflict of interest.

\section{BIBLIOGRAPHY}

1. Albers DD. Ankylosis of teeth in the developing dentition. Quintessence Int 1986;17:303-308.

2. Antoniades K, Kavadia S, Milioti K, Antoniades V, Markovitsi E. Submerged teeth. J Clin Pediatr Dent 2002;26:239-242.

3. Baccetti T. A controlled study of associated dentalanomalies. Angle Orthod 1998;68:267-274.

4. Biederman W. Etiology and treatment of tooth ankylosis. Am J Orthod 1962;48:670684.

5. Bjerklin K, Bennett J. The long-term survival of lower second primary molars in subjects with agenesis of the premolars. Eur J Orthod 2000;22:245-255.

6. Bjerklin K, Al-Najjar M, Kårestedt $\mathrm{H}$, Andrén A. Agenesis of mandibular second premolars with retained primary molars: a longitudinal radiographic study of 99 subjects from 12 years of age to adulthood. Eur J Orthod 2008;30(3):254-261.

7. Bjørk A, Skieller V. Normal and abnormal growth of themandible: a synthesis of longitudinal cephalometric implant studies over a period of 25 years. Eur J Orthod 1983;5:1-46.

8. Garib DG, Peck S, Gomes SC. Increased occurrence of dental anomalies associated with second-premolar agenesis. Angle Orthod 2009;79(3):436-441.

9. Hvaring C, Ogaard B, Stenvik A et Birkeland K. Theprognosis of retained primary molars without successors:infraocclusion, root resorption and restorations in 111 patients. Eur J Orthod 2014;36:26-30.

10. Jones J, Robinson P D. Submerging deciduous molars - an extraction in time! Dent Update 2001;28:309-311.

11. Joondeph DR, McNeill RW. Congenittally absent second premolars: an interceptive approach. Am J Orthod 1971;59:50-66.

12. Josefsson E, Brattstrom V, Tegsjo U, Valerius-Olsson $H$. Treatment of lower second premolar agenesis by autotransplantation: Four-year evaluation of eighty patients. Acta Odontol Scand 1999;57:111-115.

13. Kennedy DB. Treatment strategies for ankylosed primary molars. Eur Arch Paediatr Dent 2009;10(4):201-210.

14. Kenworthy CR, Larson BF. Incorporating retained deciduous teeth in orthodontic therapy. Am J Orthod Dentofacial Orthop 2001;119(3):202-210. 
15. Kokich VG, Kokich VO. Congenitally missing mandibular second premolars: clinical options Am J Orthod Dentofacial Orthop 2006;130(4):437-444.

16. Kokich VO Jr. Congenitally missing teeth: Orthodontic management in the adolescent patient. Am J Orthod Dentofacial Orthop 2002;121:594-595.

17. Kula K, Tatum BM, Owen D, Smith RJ, Rule J. An occlusal and cephalometric study of children with ankylosis of primary molars. J Pedod 1984;8(2):146-159.

18. Kurol J, Koch G. The effect of extraction of infraoccluded deciduous molars: A longitudinal study. Am J Orthod 1985;87:46-55.

19. Kurol J, Magnusson BC. Infraocclusion of primary molars. A histologic study. Scand J Dent Res 1984;92:564-576.

20. Kurol J. Impacted and ankylosed teeth: why, when, and how to intervene. Am J Orthod Dentofacial Orthop 2006;129(Suppl.):S86-90.

21. Kurol J. Infraocclusion of primary molars: an epidemiologic and familial study. Community Dent Oral Epidemiol 1981;9:94-102.

22. Kurol J, Thilander B. Infraocclusion of primary molars with aplasia of the permanent successor. A longitudinal study. Angle Orthod 1984;54:283-294.

23. Lindgvist B. Extraction of deciduous second molar in hypodontia. Eur J Orthod 1980;2:173-181.

24. Natiella JR, Armitage JE, Greene GW. The replantation and transplantation of teeth. Oral Surg Oral Med Oral Pathol 1970;29:397-419.

25. Northway $W$. The nuts and bolts of hemisection treatment: Managing congenitally missing mandibular second premolars. Am $J$ Orthod Dentofacial Orthop 2005;127:606-610

26. Ostler MS, Kokich VG. Alveolar ridge changes in patients with congenitally missing mandibular second premolars. J Prosth Dent 1994;71:144-149.

27. Peck S. Dental Anomaly Pattern (DAP). A new way to look at malocclusion. Angle Orthod 2009;79(5):1015-1016.

28. Polder BJ, Van'T Hof MA, Van der Linden FPGM, Kuijpers-Jagtman AM. A meta-analysis of the prevalence of dental agenesis of permanent teeth. Community Dent Oral Epidemiol 2004;32:217-226.

29. Sabri R. Management of over-retained mandibular deciduous second molars with and without permanent successors. World J Orthod 2008;9(3):209-220.

30. Shalish M, Peck S, Wassertein A, Peck L. Increased occurrence of dental anomalies associated with infraocclusion of deciduous molars. Angle Orthod 2010;80(3):440445.

31. Sidhu HK, Ali A. Hypodontia, ankylosis and infraocclusion: report of a case restored with a fibre-reinforced cerometric bridge. Br Dent J 2001;191(11): 613-616.

32. Slagsvold O, Bjercke B. Indications for autotransplantation in cases of missing premolars. Am J Orthod 1978;74:241-257.

33. Sletten D, Smith BM, Southard KA, Casko JS, Southard TE. Retained deciduous mandibular molars in adults: A radiographic study of longterm changes. Am J Orthod Dentofacial Orthop 2003;124:625-630.

34. Spear F, Mathews D, Kokich V. Interdisciplinary management of single-tooth implants. Semin Orthod 1997;3:45-72.

35. Steigman S, Koyoumdjisky-Kaye E, Matrai Y. Relationship of submerged deciduous molars to root resorption and development of permanent successors. J Dent Res 1974;53:88-93.

36. Teague AM, Barton P, Parry WJ. Management of the submerged deciduous tooth: 1. Aetiology, diagnosis, and potential consequences. Dent Update 1999;26:292-296.

37. Valencia R, Saadia M, Grinberg G. Controlled slicing in the management of congenitally missing second premolars. Am J Orthod Dentofacial Orthop 2004;125:537-543.

38. Vastardis $\mathrm{H}$. The genetics of human tooth agenesis: new discoveries for understanding dental anomalies. Am J Orthod Dentofac Orthop 2000;117:650-656.

39. Zuccati G. Therapy in cases of agenesis orthodontics. J Clin Orthod 1993;27:369-373. 